\title{
Rodadas de licitação da ANP: aspectos históricos com foco nas variáveis de julgamento licitatório
}

As rodadas de licitação da Agência Nacional de Petróleo, Gás Natural e Biocombustíveis (ANP) vêm ocorrendo no Brasil, desde a quebra do monopólio da Petrobras, através da Lei 9.478 de 1997. Desde então, foi criada a ANP e o Conselho Nacional de Pesquisas Energéticas (CNPE) com o intuito, dentre outros, de promover a livre concorrência, atrair investimentos na produção de energia e ampliar a competitividade do País no mercado internacional. A partir disso, inúmeras empresas foram criadas e outras estrangeiras passaram a fazer parte do hall de investidores e de exploradores em todo território nacional. Por vezes, o entendimento do processo de licitação é incipiente por muitos profissionais técnicos da indústria de E\&P, deixando parte das decisões e envolvimento desse processo para gestores que, por sua vez, podem ignorar aspectos técnicos fundamentais no momento da oferta para obtenção dos blocos. Almeja-se, através desse trabalho, descrever de forma sucinta e objetiva as variáveis de julgamento licitatório, ou seja, Bônus de Assinatura (BA), Programa Exploratório Mínimo (PEM) e Conteúdo Local (CL), e o como o técnico pode influenciar no momento que antecede a rodada de licitação.

Palavras-chave: Rodadas de Licitações; Blocos Exploratórios; Bônus de Assinatura; Programa Exploratório Mínimo; Conteúdo Local.

\section{ANP rounds: historical aspects focused on the variables of the bidding process}

\begin{abstract}
The bidding rounds of the National Petroleum, Natural Gas and Biofuels (ANP) have been taking place in Brazil since the fall of Petrobras' monopoly, through Law 9478 1997. Since then, the ANP and the National Council of Energy Research (CNPE) was created with the aim, among others, to promote free competition, attract investment in energy production and increase the country's competitiveness in the international market. From this, many companies were created and other foreign became part of the hall of investors and explorers throughout the country. Sometimes the understanding of the bidding process is incipient by many technical professionals in the E\&P industry, leaving part of decisions and involvement of this process for managers who, in turn, can ignore fundamental technical aspects at the time of bid to obtain the blocks. We aimed to, through this work, describe succinctly and objectively the bidding judgment variables: Signature Bonus (BA) Minimum Exploratory Program (PEM) and Local Content (CL) - and, most of all, how the technician can influence this process before the bidding round.
\end{abstract}

Keywords: Brazil Rounds; Exploration Blocks; Signature Bonus; Minimum Exploration Program; Local Content.

Topic: Engenharia de Petróleo e Gás

Reviewed anonymously in the process of blind peer.

Enock Fernandes Alves

Universidade Cidade de São Paulo, Brasil

http://lattes.cnpq.br/2570263624775114

enockmeca@yahoo.com.br

Bianca Silveira de Andrade

Universidade Federal de Sergipe, Brasil

http://lattes.cnpq.br/4227337851184201

biancasilveira@engepet.com.br
Received: 10/06/2016

Approved: 14/09/2016

\section{Referencing this:}

ALVES, E. F.; ANDRADE, B. S.. Rodadas de licitação da ANP: aspectos históricos com foco nas variáveis de julgamento licitatório. Engineering Sciences, v.4, n.1, p.29-36, 2016. DOI: http://doi.org/10.6008/SPC2318-3055.2016.001.0002 


\section{INTRODUÇÃO}

Em 3 de outubro de 1953, através da Lei 2.004 e como resultado de uma campanha popular que durou sete anos, foi criada a Petrobras, hoje a Petróleo Brasileiro S.A. Desde então, as atividades de Exploração, Produção, Refino e Distribuição de petróleo ficavam restritas à essa estatal que tinha como mola propulsora investimentos em vários setores da economia, bem como a busca da redução da dependência de petróleo e derivados proveniente de outros países.

Contudo, com a forte onda de privatizações da década de 90, veio juntamente a Lei do Petróleo (Lei $n^{\circ}$ 9478/1997), que tem como princípio e objetivo, estabelecer diretrizes junto às políticas nacionais para o aproveitamento racional das fontes de energia. Foi, portanto, estabelecido o fim do monopólio da estatal nas áreas de E\&P e, para assegurar o cumprimento das diretrizes, destaca-se como papéis fundamentais a criação do CNPE e da ANP. Ambos visando cumprir a lei citada de preservar o interesse nacional, promover o desenvolvimento, valorizar os recursos energéticos, garantir o fornecimento de derivados de petróleo em todo território nacional, promover a livre concorrência e atrair mais investimentos para a produção de energia. Partindo dos pressupostos supracitados, a Agência Nacional de Petróleo e Biocombustíveis promove as rodadas de licitações com certa regularidade.

Como atividade prévia, as licitações da ANP promovem estudos geológicos e geofísicos para identificação de potencial petrolífero e monta seu acervo com informações e dados técnicos. Por fim, põe a leilão as áreas para exploração, desenvolvimento e produção de óleo e gás. Não deixando, contudo, de fiscalizar o cumprimento dos contratos assinados pelos concessionários durante todo o período da concessão.

Portanto, um ano após a criação da ANP, começaram as rodadas, sempre buscando a participação de novos investidores (nacionais ou estrangeiros) nas atividades de E\&P. Essas licitações geram desenvolvimento econômico para o país, criação de novos empregos, aumento da renda e da competitividade das indústrias brasileiras.

Para atingir esses objetivos, alguns critérios foram implementados para o arremate dos blocos exploratórios. São eles o Bônus de Assinatura, o Programa Exploratório Mínimo e o Conteúdo Local. A soma ponderada desses critérios estabelece o ganhador do bloco, que tem como obrigação cumprir o acordado, com sansões que podem ser pagamento de multas ou, em casos extremos, a perda do bloco arrematado.

Entende-se, portanto, que as rodadas de licitações, juntamente com a fiscalização do cumprimento dos acordos, geram condições para o desenvolvimento do país e, por consequência, a otimização da produção (evitando a lavra predatória), logo, o melhor aproveitamento do potencial petrolífero do país.

\section{METODOLOGIA}

Para essa pesquisa, foi visitado o site da ANP o qual contém detalhes das rodadas de licitação. As leis mencionadas descrevem quando foram criadas a Petrobras, ANP e CNPE. Tanto o histórico de licitações quanto as variáveis das ofertas podem ser acessadas e compreendidas através do site da agência. Por fim, 
uma análise crítica é feita em cada variável do ponto de vista profissional no intuito de auxiliar na escolha desses parâmetros no momento da licitação.

\section{DISCUSSÃO TEÓRICA}

\section{Histórico de Licitações}

Conforme mencionado, a Lei 9.478/1997 pôs fim ao monopólio exercido pela Petrobras nas atividades de exploração e produção e, desta maneira, ficou determinado que outras empresas poderiam exercer as atividades supracitadas. Contudo, nas áreas que a Petrobras já tinha campos de produção, a mesma permaneceria atuando. As negociações que permitiram a estatal continuar com o direito sobre as concessões foram conhecidas como Rodada Zero.

Em 1999 ocorreu a primeira rodada de licitações. Nela, quarenta e duas companhias intentaram adquirir blocos, das quais onze arremataram blocos a serem explorados. Nesse momento, a oferta consistia em três critérios: bônus de assinatura (equivalente a $85 \%$ da nota final), percentual de serviços e bens na fase exploratória adquiridos no Brasil ( $3 \%$ da nota final) e percentual de serviços e bens adquiridos na fase de desenvolvimento adquiridos no Brasil (os 12\% restantes). Esses serviços e bens adquiridos no Brasil também são conhecidos como Conteúdo Local.

No ano posterior, foi realizada a segunda rodada com a oferta de 23 blocos (10 em terra e 13 no mar), com o objetivo principal, segundo a ANP, de aumentar e acelerar a atividade exploratória, facilitar a transferência de tecnologia, conhecimento e melhores práticas da indústria do petróleo, fixando bases para o desenvolvimento de um setor petrolífero competitivo, eficiente e dinâmico. A mudança em relação à oferta se deu no fato da imposição de um valor mínimo para o bônus de assinatura e um percentual mínimo a ser efetuado nos serviços de mão de obra nacional: 50\% na fase exploratória e 70\% na fase de desenvolvimento.

Já na terceira rodada, manteve-se a periodicidade anual e um foco maior foi dado aos blocos offshore, sendo, desta forma, ofertados 43 blocos no mar e 10 blocos em terra. Essa rodada seguiu reduzindo o tamanho dos blocos com o intuito de oferecer oportunidades a empresas com os mais variados perfis. Dos 53 blocos oferecidos, 34 foram arrematados. No quesito variável das ofertas, mantiveram-se as mesmas prerrogativas e elas continuaram na quarta rodada, realizada em 2002.

Em 2003, houve um grande marco incorporado nas licitações: o Programa Exploratório Mínimo. Nesse programa, durante o período exploratório, o concessionário se compromete a fazer uma série de atividades. Essas atividades se tornam compromisso firme junto à agência e começaram a fazer parte da composição da oferta (medida em Unidades de Trabalho, tabela 1). Resumindo, na quinta rodada, apenas $30 \%$ da oferta é composta pelo bônus de assinatura, $25 \%$ é devido ao investimento em serviços e mão de obra nacional, $30 \%$ referente a atividades a serem desenvolvidas na fase exploratória e $15 \%$ referente ao PEM em conjunto com o conteúdo local. Enquanto na quinta rodada 908 blocos foram oferecidos (apenas 101 arrematados), na sexta, 154 blocos foram concedidos a 19 empresas. Nesta rodada, a regra para arremate do bloco manteve-se semelhante ao quinto leilão. 
Tabela 1: Equivalência de Unidade de Trabalho para cumprimento do PEM.

\begin{tabular}{c|c|c|c|c|c}
\hline \multicolumn{1}{|c|}{ UNIDADES DE TRABALHO } & \multicolumn{2}{c}{$\begin{array}{c}\text { Métodos } \\
\text { Potenciais } \\
\text { (UT/Bloco) }\end{array}$} & $\begin{array}{c}\text { Geoquímica } \\
\text { (UT/Bloco) }\end{array}$ \\
\hline $\begin{array}{c}\text { SBAR-AR2, SC-AR2, SC-AR3, SES- } \\
\text { AR1, SES-AR2, SSFZA-AR1, SFZA- } \\
\text { AR2, SS-AR3 e SS-AR4 }\end{array}$ & 1000 & 0,16 & 0,80 & 0 & 0 \\
\hline SC-AP1, AP-AP3, SS-AP4 e SJ-AP & 1000 & 0,08 & 0,40 & 0 & 0 \\
\hline $\begin{array}{c}\text { SPOT-T2, SPOT-T3, SPOT-T4, SPOT- } \\
\text { T5, SREC-T2, SES-T2, SES-T4 e SES- } \\
\text { T6 }\end{array}$ & 1000 & 10 & 50 & 10 & 10 \\
\hline
\end{tabular}

Fonte: Edital da 4a Rodada de licitações da ANP.

Na sétima rodada, ocorrida em 2005 , dentre as variáveis da oferta, o CL veio com uma pequena modificação: os percentuais mínimos e máximos para a fase exploratória e os para a etapa de desenvolvimento. Eles foram definidos de acordo com a lâmina d'água (LDA) do referido bloco (Tabela 2). Para a apuração das ofertas, o bônus de assinatura foi responsável por $40 \%$ do cálculo final da nota, o PEM também por $40 \%$ e o $\mathrm{CL}$ foi de $20 \%$, sendo $5 \%$ referentes à fase exploratória e $15 \%$ à etapa de desenvolvimento.

Tabela 2: Percentuais de investimentos locais mínimos e máximos a serem pontuados nas ofertas, para a fase de exploração e etapa de desenvolvimento.

\begin{tabular}{c|c|c|c|c}
\hline \multirow{2}{*}{ Localização do Bloco } & \multicolumn{2}{|c|}{ Fase de Exploração } & \multicolumn{2}{c}{ Etapa de Desenvolvimento } \\
\cline { 2 - 5 } & Mínimo (\%) & Máximo (\%) & Mínimo (\%) & Máximo (\%) \\
\hline $\begin{array}{c}\text { Águas Profundas } \\
\text { LDA > 400m }\end{array}$ & 37 & 55 & 55 & 65 \\
\hline $\begin{array}{c}\text { Águas Rasas } \\
100 \text { m <LDA } \leq 400 m\end{array}$ & 37 & 55 & 55 & 70 \\
\hline $\begin{array}{c}\text { Águas Rasas } \\
\text { LDA } \leq 100 m\end{array}$ & 51 & 60 & 63 & 85 \\
\hline Terra & 70 & 80 & 77 & 65 \\
\hline
\end{tabular}

Fonte: Edital da 7a Rodada de licitações da ANP.

Devido a uma liminar judicial, a oitava rodada de licitações, programada para ocorrer nos dias 28 e 29 de novembro de 2006, foi cancelada. O Conselho Nacional de Política Energética (CNPE), em dezembro de 2012, determinou que a ANP efetivasse o cancelamento definitivo dessa rodada.

De volta em 2007, a nona rodada, no quesito cálculo da nota final para arremate, manteve-se as regras da sétima rodada. Naquele momento, foram arrematados 117 blocos por 24 empresas operadoras. Na rodada dez, tanto o percentual-como a fórmula de cálculo permaneceram, a diferença foi que a gamaespectometria, métodos gravimétricos, magnetométricos e eletromagnéticos começaram a valer mais na equivalência de UTs para cumprimento do PEM. Fato que não se manteve na rodada onze. De maneira geral, apenas os blocos em bacias maduras puderam ter equivalência de UTs referente a dados gravimétricos, magnéticos e gamaespectométricos.

O cálculo das variáveis da oferta não tem sofrido modificações nos últimos anos, contudo, na décima segunda rodada, um novo critério foi introduzido (e manteve-se na décima terceira rodada) para a validação das Unidades de Trabalho: para blocos localizados em determinados setores, o primeiro poço perfurado na Fase de Exploração deveria atingir o objetivo estratigráfico mínimo exigido e realizar uma série de perfis de 
poços, amostragens e análises mínimas outrora não solicitadas. Fez-se necessário, portanto, que as empresas operadoras levassem em consideração os altos custos envolvidos nesses requisitos na hora de entrar no leilão de um bloco.

\section{Variáveis das Ofertas}

Acredita-se, desta forma, que doravante o critério de julgamento das variáveis das ofertas deve manter-se o mesmo. Logo temos que o cálculo atual utilizado descrito nas equações 1 a 5, pode, e deve ser bem entendido por todos que estão envolvidos no processo licitatório.

$$
\begin{aligned}
& \text { Nota } 1=40 \times \frac{\text { PEM ofertado (UTs) }}{\text { Maior PEM ofertado (UTs) }} \\
& \text { Nota } 2=40 \times \frac{\text { Bônus de Assinatura ofertado (R } \$)}{\text { Maior Bônus de Assinatura Ofertado (R\$) }} \\
& \text { Nota } 3=5 \times \frac{\text { CL ofertado na Fase de Exploração (\%) }}{\text { Maior CL ofertado na Fase de Exploração (\%) }} \\
& \text { Nota } 4=15 \times \frac{\text { CL ofertado na Etapa de Desenvolvimento (\%) }}{\text { Maior CL ofertado na Etapa de Desenvolvimento (\%) }} \\
& \text { Nota Final }=\text { Nota } 1+\text { Nota } 2+\text { Nota } 3+\text { Nota } 4+\text { Nota } 5
\end{aligned}
$$

Tanto para o PEM, quanto CL e o Bônus de Assinatura, a agência estipula um valor mínimo para cada um deles, sabendo que, caso o valor mínimo não seja ofertado, a concessionária é desclassificada.

\section{Programa Exploratório Mínimo}

Entende-se como Programa Exploratório Mínimo, o conjunto de atividades a serem executadas pelo concessionário durante o Primeiro Período da Fase de Exploração. Essas atividades, expressas em UTs, têm pesos diferentes de acordo com cada edital. Contudo, nos últimos anos, a regra tem se mantido a mesma.

Para blocos terrestres, em bacias maduras, temos as equivalências de UTs conforme Tabela 3. E o valor da garantia financeira, por Unidade de Trabalho, tem sido de $\mathrm{R} \$ 3.800,00$.

Tabela 3: Equivalência das Unidades de Trabalho.

\begin{tabular}{c|c|c}
\hline \multirow{2}{*}{ Aquisição Sísmica } & $2 \mathrm{D}(\mathrm{UT} / \mathrm{km})$ & 9,849 \\
\cline { 2 - 3 } & $3 \mathrm{D}(\mathrm{UT} / \mathrm{km})$ & 28,436 \\
\hline \multirow{2}{*}{ Reprocessamento Sísmico } & $2 \mathrm{D}(\mathrm{UT} / \mathrm{km})$ & 0,284 \\
\cline { 2 - 3 } & $3 \mathrm{D}(\mathrm{UT} / \mathrm{km})$ & 0,707 \\
\hline \multirow{2}{*}{ Aquisição Eletromagnética } & (UT/Receptor) & 0,760 \\
\hline Poço & (UT/km) & 1000 \\
\hline \multirow{2}{*}{ Métodos Potenciais } & (UT/Poço) & 0,128 \\
\hline & GRAV (UT/km) & 0,640 \\
\cline { 2 - 3 } & GRAV-GRAD (UT/km) & 0,128 \\
\cline { 2 - 3 } & MAG(UT/km) & 0,128 \\
\hline Gamaespectometria & (UT/km) & 0,238 \\
\hline
\end{tabular}


Contudo, na escolha da oferta, deve-se ter em mente, exatamente, quais atividades serão executadas durante o primeiro período exploratório. Nos blocos terrestres de bacias maduras, esse período dura três anos contados a partir da data de assinatura do contrato.

Para uma boa escolha da oferta desse parâmetro, faz-se necessário estipular criteriosamente as tarefas a serem executadas e, desta forma, calcular de maneira consciente as UTs a serem ofertadas. Por exemplo, muitos blocos em bacias maduras têm cerca de trinta quilômetros quadrados de área. Portanto, ao analisar um bloco, o concessionário deve verificar o acervo de dados disponibilizados na ANP para ter uma ideia de quais mais ele precisará para avaliar bem o bloco a ser adquirido. Caso algumas linhas 2Ds já existam, pode-se planejar a aquisição de dados sísmicos 3D em todo o bloco (em dados terrestres, descontar a área com cidade ou qualquer impedimento para aquisição dos dados), ou ainda na parte com maior interesse geológico. Considerando $30 \mathrm{~km}^{2}$, para aquisição sísmica de dados 3D, já seriam cerca de 853 UTs.

O concessionário pode ainda adquirir dados eletromagnéticos, por dizer, utilizando 26 receptores, o que daria 149 UTs. Se, portanto, acreditar que com esses dados, pode-se avaliar de maneira satisfatória o bloco, uma oferta de 1000 UTs (soma das UTs da sísmica com o levantamento eletromagnético) é suficiente.

Outro caso poderia ser um bloco onde já exista uma grande malha de linhas sísmicas 2D, poços perfurados e abandonados, assim como dados gravimétricos e magnetométricos em abundância. A estratégia pode ser adquirir os dados pré-existentes na ANP e, no Primeiro Período Exploratório, fazer apenas um poço exploratório, confirmando ou não a acumulação de hidrocarbonetos. Nesse caso, a estratégia também seria ofertar 1000 UTs.

O fato é que, ao se comprometer com as Unidades de Trabalhos, a empresa não está se responsabilizando com alguma atividade específica. Logo, após a licitação, se o concessionário mudar de ideia, pode ainda optar por outras atividades, de maneira que alcance, no mínimo, 1000 UTs.

Uma mudança na décima primeira rodada foi que, caso não sejam cumpridas até dez por cento das UTs prometidas, o concessionário pode optar por pagar o dobro do valor referente à garantia financeira das UTs restantes e, desta forma, o compromisso estará cumprido.

\section{Bônus de Assinatura}

O valor financeiro a ser pago pelo bloco é denominado Bônus de Assinatura. O mesmo deve ser pelo menos, o valor mínimo exigido pela ANP. Valor esse que varia bloco a bloco. A escolha desse parâmetro deve ser feita a partir da expectativa de lucro estimado no projeto, ou seja, o Valor Monetário Esperado (VME). Gandra (2013) descreve alguns critérios de seleção de projetos de investimentos em ambientes de risco. Nesse artigo, ele apresenta, em detalhes, o Fluxo de Caixa clássico em Projetos de Exploração e Produção (Figura 1). Logo, o lucro estimado na vida do projeto, trazido para o valor presente e ponderado pela probabilidade de sucesso da oportunidade definirá o VME do projeto.

Para essa avaliação econômica, são levados em consideração os custos relativos aos estudos regionais feitos antes da licitação, valores a serem investidos em aquisição de dados geofísicos (sísmica, métodos potenciais, eletromagnéticos, etc), perfuração de poços exploratórios, avaliação dos poços, poços 
de desenvolvimento, custos para escoamento da produção, custos operacionais, impostos, royalties, custo de abandono dos poços e os demais custos que podem ocorrer no projeto. Por fim, o faturamento com o hidrocarboneto a ser produzido, levará ao lucro do projeto.

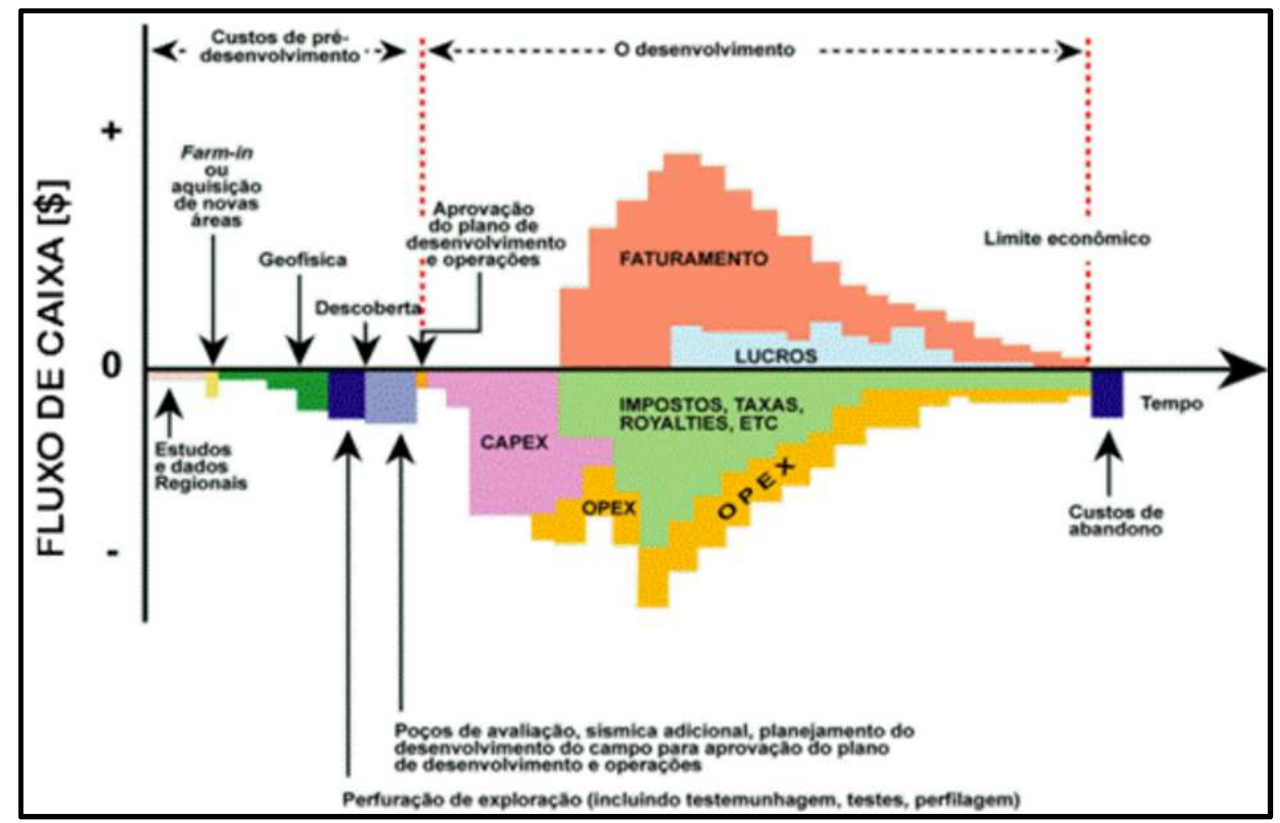

Figura 1: Fluxo de Caixa em Projetos de E\&P (GANDRA, 2013).

Após esses cálculos, pode-se destinar entre vinte e trinta por cento do VME, para pagar o bônus de assinatura. Portanto, a estimativa mais próxima possível da jazida a ser descoberta é de suma importância na valoração e no valor a ser investido.

\section{Conteúdo Local}

A proporção dos investimentos nacionais aplicados em um determinado bem ou serviço é denominado Conteúdo Local. Segundo Vazquez (2010), "A ideia central da exigência de CL é dar preferência à contratação de fornecedores e mão-de-obra brasileiros, desde que estes ofereçam condições de preço, prazo e qualidades equivalentes às de fornecedores estrangeiros". Ele ainda afirma que dar condições de competitividade às empresas brasileiras, bem como fomentar o desenvolvimento tecnológico e a capacitação de recursos humanos, gerando emprego e renda para o país é o cerne dessa política.

Para essa variável, necessita-se compreender bem o item PEM e, a partir dele, calcular quanto do investimento poderá ser feito com produtos e serviços brasileiros para ofertar, dessa forma, um número ótimo entre custo e exequibilidade. Respeitando, sempre, os limites mínimos e máximos que constam no Edital de Licitações.

Vazquez (2010), conclui que, apesar do Conteúdo Local ser a variável das ofertas que impulsiona o desenvolvimento do setor nacional, na sua visão, a Petrobras, apesar de estatal, agiu de maneira semelhante às concorrentes de nível internacional, apresentando comportamento impulsionador do desenvolvimento nacional semelhante as demais. 


\section{CONCLUSÕES}

Apesar de ser, aparentemente, uma decisão gerencial, a escolha das ofertas a serem apresentadas junto a Agência Nacional de Petróleo, devem ser acompanhadas bem de perto por profissionais técnicos capacitados de diversas áreas: geólogos, geofísicos, engenheiros, contadores, etc. Valores exequíveis e bem planejados de Programa Exploratório Mínimo levam a boas referências na escolha do valor a ser ofertado de Bônus de Assinatura e, também, na escolha do correto percentual no Conteúdo Local.

\section{REFERÊNCIAS}

BRASIL. Lei n. 9478 de 06 de agosto de 1997. Brasília: DOU, 1997.

BRASIL. Lei n. 2004 de 03 de outubro de 1953. Brasília: DOU, 1953.

GANDRA, R. M.. Índice de Sharpe como critério de seleção de projetos de investimentos em ambiente de risco. PMO Academy, 2013.

VAZQUEZ, F. A.. Análise crítica das ofertas das rodadas de licitações da ANP, com foco nas variáveis do julgamento do processo licitatório: conteúdo local, bônus de assinatura e programa exploratório mínimo. Monografia (Graduação em Engenharia de Petróleo) - Universidade Federal do Rio de Janeiro, Rio de Janeiro, 2010. 